\title{
The population mean predicts the number of deviant individuals
}

\author{
Geoffrey Rose, Simon Day
}

\section{Abstract}

Objective-To examine the relation between the prevalence of deviation and the mean for the whole population in characteristics such as blood pressure and consumption of alcohol.

Design-Re-examination of standardised data from the Intersalt study, an international, multicentre study on the determinants of blood pressure.

Setting and subjects-Samples of adults representing 52 populations in 32 countries.

Main oucome measures-The relations, expressed as correlation coefficients, between the mean population values for blood pressure, body mass index, alcohol consumption, and sodium intake and the prevalence of, respectively, hypertension ( $\geqslant 140 \mathrm{~mm} \mathrm{Hg}$ ), obesity (body mass index $\left.\geqslant 30 \mathrm{~kg} / \mathrm{m}^{2}\right)$, high alcohol intake ( $\geqslant 300 \mathrm{ml} /$ week), and high sodium intake ( $\geqslant 250 \mathrm{mmol} /$ day).

Results - There were close and independent associations between the population mean and the prevalence of deviance for each of the variables examined: correlation coefficients were 0.85 for blood pressure, 0.94 for body mass index, 0.97 for alcohol intake, and 0.78 for sodium intake.

Conclusions - These findings imply that distributions of health related characteristics move up and down as a whole: the frequency of "cases" can be understood only in the context of a population's characteristics. The population thus carries a collective responsibility for its own health and well being, including that of its deviants.

\section{Introduction}

It is commonly supposed that there is a clear distinction between normality and deviance, whether the attribute is physiological (like blood pressure), behavioural (like eating or drinking), or social (like aggression). This view is attractive because it focuses attention on individuals who clearly have problems and at the same time reassures the majority: they are all right and not responsible for the deviant minority. Thus, whatever Pickering may have said, ' hypertension is still widely felt to be something different from the normal variation of blood pressure.

If normality and deviance are indeed independent then the "normal" majority are free to disapprove of the deviants. Heavy drinkers of alcohol are condemned, but moderation is beyond criticism. Obesity is bad, but average weight is socially acceptable (even in overweight populations). Football hooligans are deviant reprobates, but, in a market economy especially, less conspicuous aggression is usual and actually encouraged. In each case the population as a whole disowns the tail of its own distribution: hypertension, obesity, alcoholism, and other behavioural problems can then be considered in isolation.

But can the problems of the deviant minority really be understood and managed as though they were independent of the characteristics of the rest of the population? We used a unique data resource to study this question as it applies to several health related characteristics and to consider some implications of the clear answer which emerged.

\section{Data and methods}

The Intersalt study ${ }^{2}$ was set up to examine the relation of blood pressure to salt intake and other variables; but we used the data here for a different purpose. The data came from a survey of population samples from 52 centres in 32 countries, including in all 10079 men and women aged $20-59$ years. The study populations covered a wide range of societies, from the Yanomamo Indians of Brazil to urbanised Westerners: 31 were in Europe (including the United Kingdom and the Soviet Union), eight in the Americas, 11 in Asia, and two in Africa. The study used standardised questionnaires and examination methods, centrally trained and tested observers, and extensive quality control; thus the data are acceptably valid for cross cultural comparisons.

Our analysis considered four variables: systolic blood pressure, body mass index, and the intakes of alcohol and sodium (results for diastolic blood pressure were almost identical with those for systolic). For each of these variables the 52 centres differed widely, both in population mean values and in the prevalence of high values (table I). The high values were defined either conventionally (systolic blood pressure, body mass index, alcohol) or by the top decile point for the whole study population (sodium). Figure 1 contrasts the systolic blood pressure distributions of the five populations with the highest means and the five with the lowest.

Our analysis examined the relation across populations between these variations in means and prevalence rates. To the extent that the population distributions

TABLE I-Range of observed values of population mean and prevalence rates of high values across 52 centres

\begin{tabular}{lccc}
\hline & \multirow{2}{*}{$\begin{array}{c}\text { Range } \\
\text { of } \\
\end{array}$} & \multicolumn{2}{c}{ High values } \\
\cline { 3 - 4 } & $\begin{array}{c}\text { population } \\
\text { means }\end{array}$ & Definition & $\begin{array}{c}\text { Prevalence } \% \\
\text { (grand mean) }\end{array}$ \\
\hline Systolic blood pressure $(\mathrm{mm} \mathrm{Hg})$ & $96-133$ & $\geqslant 140$ & $0-32(10 \cdot 3)$ \\
Body mass index $\left(\mathrm{kg} / \mathrm{m}^{2}\right)$ & $21 \cdot 2-31 \cdot 2$ & $\geqslant 30$ & $0-51(12 \cdot 5)$ \\
Alcohol intake $(\mathrm{ml} / \mathrm{week})$ & $0-543$ & $\geqslant 300$ & $0-68(12 \cdot 8)$ \\
Sodium intake $(\mathrm{mmol} /$ day $)$ & $1-212$ & $\geqslant 250$ & $0-42(10 \cdot 8)$ \\
\hline
\end{tabular}

Correspondence to: Professor Rose. 
shift up or down as a whole, retaining the same shape, then mean and prevalence will correlate; but if the shape of the distribution changes-as by changing skewness - then mean and prevalence could be independent. Correlations were examined visually by scatter diagrams and summarised by Pearson coefficients (the Spearman coefficients were almost identical). These correlations indicated how far a knowledge of the population mean would predict the prevalence of deviance.

This method of testing did not distinguish between a correlation due to entire distributional shifts from an anchoring of the main part of the distribution but with varying degrees of positive skewing. In the latter case the high values, although independent of the characteristics of the main population, would contribute to the overall mean and in this way produce "autocorrelation." To estimate the independent component of the association, correlations were also calculated between the prevalence of high values and the mean of the

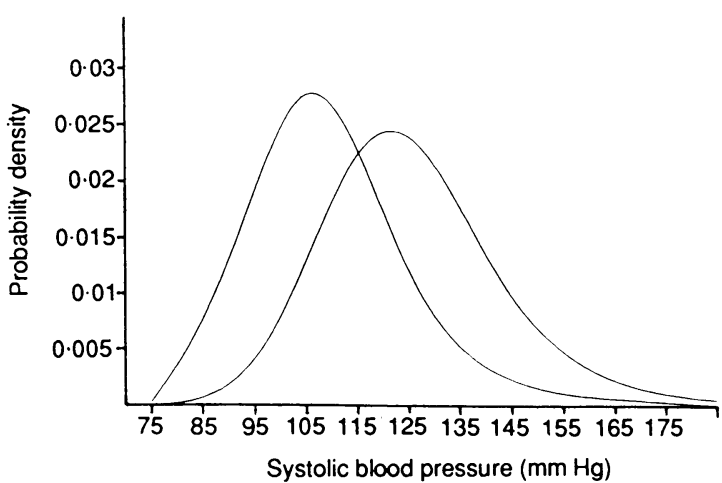

FIG 1-Distributions of systolic blood pressures for averages of the five populations with the lowest mean values and the five with the highest remainder of the population, excluding those high values.

\section{Results and comment}

Figure 2 displays the results for the four variables, including the Pearson correlation coefficients and the slopes of the linear regressions. In each case the correlation was high $(\mathrm{r}=0.78$ to 0.97$)$ : thus a knowledge of the mean value for the population indicated the proportion of deviant individuals, even though these 52 study populations differed so widely in their health and cultural characteristics.

Only in the case of alcohol was the relation linear over the whole range. For the other variables there was a critical value of the mean below which the prevalence of deviant (high) individual values was effectively zero; above these values, however, the relation was roughly linear, with little scatter. Thus for these three variables the linear correlation and regression values underestimated the true closeness and strength of the relations: non-linear models would have given a better fit.

Allowing for this underestimation we could therefore predict the reduction in the mean value that would produce a specified reduction in the prevalence of high values (table II). For systolic blood pressure in most populations a reduction of $1 \mathrm{~mm} \mathrm{Hg}$ in the population mean value would be associated with a lowering of the prevalence of hypertension of about $1 \%$. Thus in a population with a current prevalence of hypertension of $15 \%$ a fall of $5 \mathrm{~mm} \mathrm{Hg}$ in mean systolic pressure would correspond to a new prevalence of $10 \%$-that is, one third fewer hypertensive patients by this definition (but the choice of the definition is probably not highly critical).
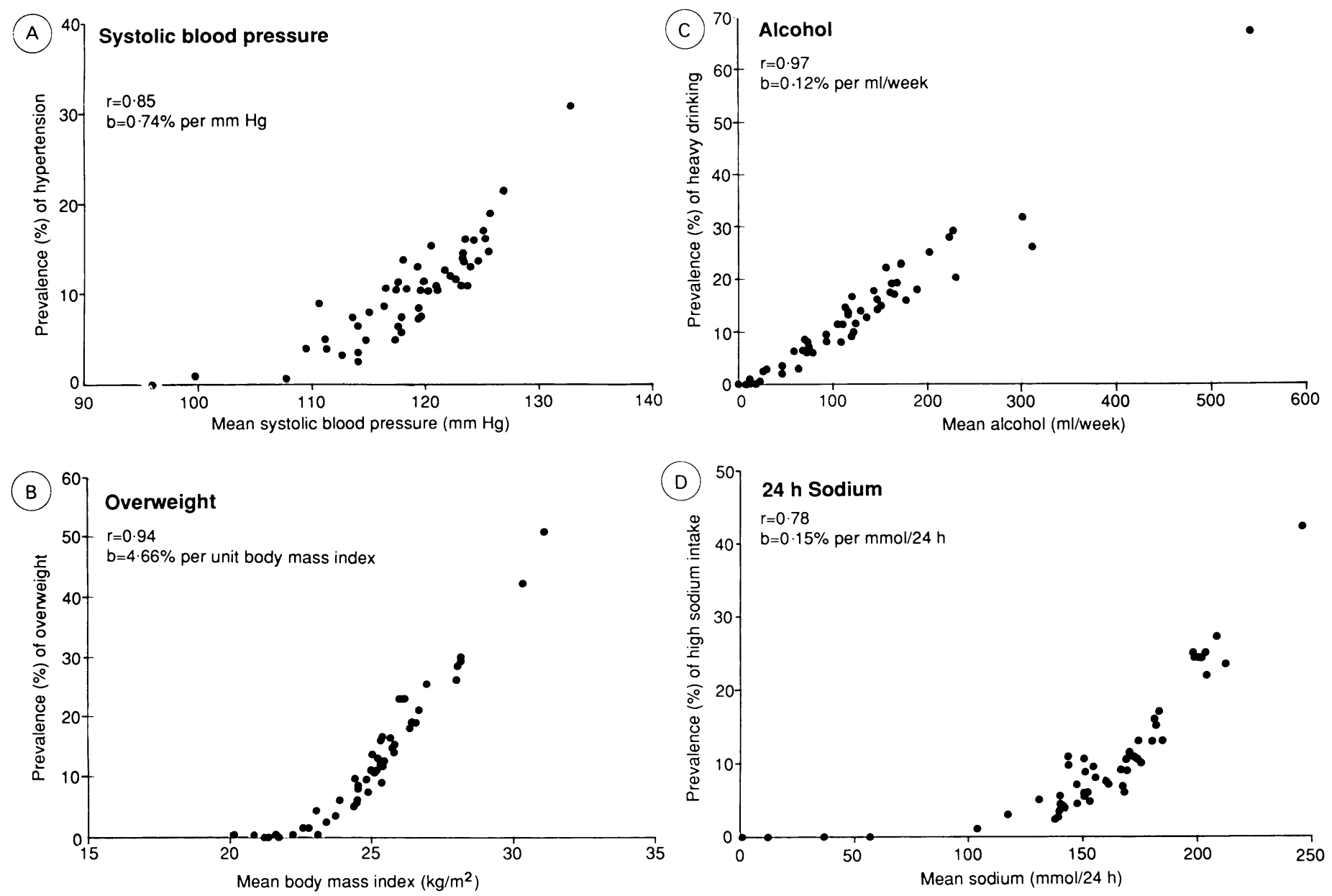

FIG 2-Relation between population mean and the prevalence of deviant ( high) values across 52 population samples from 32 countries (men and women aged 20-59); (A) systolic blood pressure, $(B)$ body mass index, $(C)$ alcohol intake, $(D)$ urinary 24 hour sodium excretion 
TABLE II - Predicted percentage fall in prevalence of high values (and $95 \%$ confidence intervals) after specified reductions in population mean values. (See text for details)

\begin{tabular}{|c|c|c|}
\hline Variable & $\begin{array}{l}\text { Reduction } \\
\text { in } \\
\text { mean values }\end{array}$ & $\begin{array}{c}\text { Predicted fall in prevalence }(\%) \\
\text { of high values } \\
(95 \% \text { confidence interval })\end{array}$ \\
\hline Systolic blood pressure & $5 \mathrm{~mm} \mathrm{Hg}$ & $15-11 \cdot 3(10.7$ to 11.9$)$ \\
\hline Body weight & $1 \mathrm{~kg}$ & $6-4 \cdot 4(4 \cdot 2$ to $4 \cdot 5)$ \\
\hline Alcohol intake & $15 \mathrm{ml} /$ week & $17-15 \cdot 2(15 \cdot 1$ to $15 \cdot 4)$ \\
\hline Sodium intake & $50 \mathrm{mmol} / \mathrm{day}$ & $23-15.6(13.9$ to $17 \cdot 3)$ \\
\hline
\end{tabular}

TABLE III-Correlation coefficients and linear regression slopes relating prevalence of high values with the mean values in the remainder of the population ( 52 centres)

\begin{tabular}{|c|c|c|}
\hline & $\begin{array}{l}\text { Correlation } \\
\text { coefficient }\end{array}$ & $\begin{array}{l}\text { \% Change in prevalence of high } \\
\text { values per unit change in } \\
\text { population mean }\end{array}$ \\
\hline $\begin{array}{l}\text { Systolic blood pressure } \\
\text { Body mass index } \\
\text { Alcohol intake } \\
\text { Sodium intake }\end{array}$ & $\begin{array}{l}0 \cdot 76^{\star} \\
0 \cdot 78^{\star} \\
0 \cdot 64^{\star} \\
0 \cdot 64^{\star}\end{array}$ & $\begin{array}{l}1.0 \% \text { per } \mathrm{mm} \mathrm{Hg} \\
6.9 \% \text { per } \mathrm{kg} / \mathrm{m}^{2} \\
0.24 \% \text { per } \mathrm{ml} / \text { week } \\
0.15 \% \text { per } \mathrm{mmol} / \text { day }\end{array}$ \\
\hline
\end{tabular}

${ }^{\star} \mathrm{p}<0 \cdot 0001$.

For body mass index the correlation over most of the range was almost perfect. For a population such as that of the United Kingdom, with a mean body mass index around 25 , a lowering of average weight by $1 \mathrm{~kg}$ would correspond to a fall in the prevalence of overweight from around $6 \%$ to $4 \%$ (a reduction of one third).

The pattern for the two behavioural variables resembled that for the two physical characteristics. Alcohol intake achieved the highest of all the correlations between mean and prevalence $(r=0.97)$, aided by the fact that a far outlying point (from Mexico, with an estimated mean intake of $543 \mathrm{ml} /$ week) fell exactly on the straight line. For the three United Kingdom centres (Birmingham, Cardiff, Belfast) the estimated mean intake was $150 \mathrm{ml} /$ week; here a mean reduction of $15 \mathrm{ml} /$ week (10\%) would correspond to a fall of around $10 \%$ in the number of heavy drinkers. The overall linear slope for 24 hour sodium was distorted by the absence of any individuals with high intakes when the population mean was below $100 \mathrm{mmol} / 24$ hour. Above $150 \mathrm{mmol} / 24$ hour the relation was linear, and an average reduction from 200 to $150 \mathrm{mmol} /$ day would correspond to an approximate halving of the prevalence of high values.

Calculation of age and sex specific values showed no large or consistent differences between the subgroups.

These results described the simple relations between mean and prevalence and how to predict one from the other; but to assess the degree of independence in the relations we had to repeat the calculations after first excluding the high values from estimates of the mean (table III).

The new correlation coefficients were inevitably smaller because the element of autocorrelation had been removed but they remained large and highly significant. The coefficients of the two physical characteristics diminished less than those for alcohol and sodium intake, suggesting that for the two behavioural variables the prevalence of deviance was less completely dependent on the rest of the population.

The slopes, measuring the strength of the relation, were all increased in the new calculations. Again this was statistically inevitable: the spread of prevalence rates was the same as before but the spread of the means was diminished by the removal of the high values, which therefore increased the slope of the regression.

\section{Discussion}

Three of the four study variables (blood pressure, obesity, and sodium intake) were measured objectively by trained and tested observers using standardised methods. There were no evident biases here that might have created false associations. In the case of alcohol intake heavy drinking might have been more freely reported in communities where the average intake was high, thus tending to create a false correlation between mean and prevalence. Nevertheless, this is unlikely to have made more than a marginal contribution to the extremely close observed correlation $(r=0.97)$. Contrariwise, the estimates of association for all four variables will have been diluted by measurement errors, perhaps to an important extent.

The results show that for these characteristics, both physical and behavioural, the population mean and the prevalence of deviant values are closely related. Across a diverse selection of societies the average blood pressure predicts the number of hypertensive people; the average weight the number of fat people; the average alcohol intake the number of heavy drinkers; and the average salt consumption the number with excessive salt intake. The distribution of each of these variables moves up or down as a coherent whole (fig 1): the tail belongs to the body, and the deviants are a part of the population.

The results show this to be a geographically worldwide phenomenon. It is hard to see how it could fail also to apply to temporal changes within a population, implying that changes in population characteristics will produce predictable changes in the size of the deviant subgroup. This, however, requires confirmation.

This inevitable relationship of tail and distribution applied to each of the variables that could be assessed from the available data (including also height and heart rate, unpublished and not reported here). It has been suspected previously, from a smaller data base, for alcohol ${ }^{3}$ and for senile dementia ${ }^{4}$ and it is known to be relevant also to birth weight. ${ }^{5}$ It may well apply to many physical and mental attributes, to behavioural and environmental determinants of health, and to societal problems such as aggression. These hypotheses can be put to the test wherever standardised continuous measures have been applied across a number of populations or subgroups and the results recorded as distributions.

There are profound implications here for researchers, for preventive policy, and for societies and their governments.

\section{Implications}

\section{FOR RESEARCH}

The original grant application for the Intersalt study (from which these data derived) was turned down by a national funding council because "research into hypertension should concentrate on individuals, not populations." It is now clear that the problem of the high risk deviant minority can be understood only when considered in the context of the whole population. The prevalence of hypertension, and of many other markers of deviance, is a secondary phenomenon whose underlying explanation must be sought among the population as a whole.

Researchers commonly approach a population study with the assumption that the interest relates to a distinct subcategory of "cases"; en route to that goal they must make measurements op the whole sample, but thereafter they do not consider them further. Thus psychiatrists interested in depressive illness report only the prevalence of what they recognise as "cases of depression," and their data on the population distributions of depression scores become inaccessible. The generalisability of the ideas we have presented here cannot be tested, not because the right measurements have never been made but because they have been thought irrelevant and discarded. 
If the central tendency of the population distribution is crucially important then much more research is needed to understand its determinants. If we want to discover the causes of hypertension, obesity, alcoholism, depression, violence, and so on we need to study the determinants of average blood pressure and weight, average alcohol intake, average population "mood," intellectual performance, aggression, etc. The study of the average is crucial also to understanding better the dynamics of social change and of the interactions (possibly two way) between the majority and the deviants.

\section{FOR PREVENTION}

Traditional preventive strategy is concerned with identifying and helping minorities with special problems, by treating their risk factors or seeking changes in their behaviour. The underlying aim is to truncate the risk distribution, eliminating the high tail but not interfering with the rest of the population. ${ }^{6}$ In practice such truncation proves hard or impossible to achieve. As our results show, the spread of a distribution is not readily compressed. The close link between mean and prevalence implies that to help the minority the "normal" majority must change.

\section{FOR SOCIETY AND GOVERNMENT}

It suits society to alienate its problem minorities and to regard them as independently responsible for their problems; but if the tail belongs to the distribution and the minorities' problems exist as a consequence of the majority's attributes then it is no longer possible to regard normal (majority) behaviour as of no wider consequence. The way that most people eat, drink, and behave, even if it were harmless to themselves (which is often not the case), may determine how many others, more vulnerable, will suffer as a consequence. The health of society is integral.

This view is unwelcome to governments. It is cheaper, and politically safer, to support special measures for needy minorities than to change general social and economic policies that affect the whole population. The policy on alcohol, for example, implies highlighting the problem of heavy drinkers while condoning "drinking in moderation"; and the policy on violence is to blame a small minority of extremists, while ignoring factors which influence aggression in society as a whole. What is needed is an acceptance of collective responsibility for the population's health and social well being.

We are grateful to the Intersalt study editorial committee for permission to use some unpublished data.

1 Pickering G. High blood pressure. 2nd ed. London: Churchill, 1968.

2 Intersalt Cooperative Research Group. Intersalt: an international study of electrolyte excretion and blood pressure. Results for 24 hour urinary sodium and potassium excretion. Br Med F 1988;297:319-28.

3 Skog O-JS. The collectivity of drinking cultures: a theory of the distribution of alcohol consumption. Br f Addict 1985;80:83-99.

4 Gurland BJ, Copeland JRM, Kelleher MJ, Kuriansky J, Sharpe L, Dean L. The mind and mood of ageing: the mental health problems of the community elderly in New York and London. New York: Haworth Press, 1983:70.

5 Kramer MS. Determinants of low birth weight: methodological assessment and meta-analysis. Bull WHO 1987;65:663-737.

6 Rose G. Sick individuals and sick populations. Int $\mathcal{F}$ Epidemiol 1985;14:32-8.

(Accepted 8 August 1990)
University of Papua New Guinea, Boroko, Papua New Guinea

P A G Gibson, MRCP, lecturer in child health

Port Moresby General Hospital, Boroko, Papua New Guinea

A McClelland, MRCGP, medical officer

Correspondence to: $\mathrm{Dr}$ P A G Gibson, 15 Bedford Road, Harrow, Middlesex HAl 4LY.

BrMed f 1990;301:1034-6

\title{
How To Do It
}

\section{Visit a health centre in a developing country}

\author{
P A G Gibson, A McClelland
}

Most people in the world will not see a doctor when they are sick. Their nearest health worker will be a primary health care worker based in a village, aid post, or health centre. These health workers at the periphery of the health care system experience major problems of lack of supervision, leadership, supplies, and support. It is increasingly realised that training workers and posting them to rural health centres is not enough to ensure delivery of the quality and quantity of health care required to reach the goal of health for all by the year 2000. To reach this goal these workers require appropriate supervision.

Supervision has been defined as the overall range of measures to ensure that personnel carry out their activities effectively and become more competent at their work. The supervision of health centres is often best provided by district medical officers based in hospitals. As an important part of this process is visiting the peripheral health workers we will describe

\section{Main components of a health centre visit}

- Good communication with all health workers

- Teaching and discussion

- Seeing patients with health workers

- Tour of health centre

- Assessing performance

- Follow up and feedback to health centre some points that a medical officer needs to bear in mind when planning and making a visit to a health centre. This protocol will need adjustment to suit local conditions and could be modified for use by, for example, a visiting pharmacist or specialist obstetrician.

\section{Communication}

Good communication is very important for the optimum functioning of any health system. All means available should be used to increase the quality and quantity of communication in primary health carefor example, radio, telephone, correspondence (reports, newsletters, feedback on referred patients), and ambulance or vehicle connections. A visit is an opportunity for the highest quality communication - and there is no substitute for it. The more regular and frequent that visits can be, the better. If possible, visits should be arranged for different days so as to include different aspects of health centre work: antenatal clinic, well baby clinic, tuberculosis and leprosy clinic, village patrol, aid post visit, and community health meeting. The best arrangement is if the same person can make repeated visits and build up a good relationship with the staff.

Once the time and date of the visit have been decided it is very important to keep to it, whether it is a visit every second Thursday of the month or once every six months. The ever demanding hospital workload must not be allowed to interfere with the important but 